\title{
Overcoming Pre-Fertilization Barriers in Intertribal Crosses between Anemone coronaria L. and Ranunculus asiaticus L.
}

\author{
Emmy Dhooghe ${ }^{1, * \mathbb{D}}$, Dirk Reheul ${ }^{2}$ and Marie-Christine Van Labeke ${ }^{2}$ (D) \\ 1 Plant Sciences Unit, Flanders Research Institute for Agricultural, Fisheries and Food Research (ILVO), \\ Caritasstraat 39, 9090 Melle, Belgium \\ 2 Department Plants and Crops, Faculty of Bioscience Engineering, Ghent University, Coupure Links 653, \\ 9000 Ghent, Belgium; dirk.reheul@ugent.be (D.R.); mariechristine.vanlabeke@ugent.be (M.-C.V.L.) \\ * Correspondence: emmy.dhooghe@ilvo.vlaanderen.be
}

Citation: Dhooghe, E.; Reheul, D.; Van Labeke, M.-C. Overcoming Pre-Fertilization Barriers in Intertriba Crosses between Anemone coronaria L. and Ranunculus asiaticus L. Horticulturae 2021, 7, 529. https:// doi.org/10.3390/horticulturae7120529

Academic Editors: Douglas D. Archbold and Sergio Ruffo Roberto

Received: 21 September 2021 Accepted: 26 November 2021 Published: 29 November 2021

Publisher's Note: MDPI stays neutral with regard to jurisdictional claims in published maps and institutional affiliations.

Copyright: (c) 2021 by the authors. Licensee MDPI, Basel, Switzerland. This article is an open access article distributed under the terms and conditions of the Creative Commons Attribution (CC BY) license (https:// creativecommons.org/licenses/by/ $4.0 /)$.

\begin{abstract}
Hybridization in flowering plants depends, in the first place, on the delivery of pollen to a receptive stigma and the subsequent growth of pollen tubes through the style to the ovary, where the sperm nucleus of the pollen grain can ultimately fertilize the egg cell. However, reproductive failure is often observed in distant crosses and is caused by pre- and/or post-zygotic barriers. In this study, the reproductive pre-fertilization barriers of intertribal crosses between Anemone coronaria $\mathrm{L}$. and Ranunculus asiaticus L., both belonging to the Ranunculaceae, were investigated. Despite the incongruity of intertribal crosses between $A$. coronaria and $R$. asiaticus having been of low intensity at the stigmatic level, interstylar obstructions of the pollen tube growth occurred, which confirmed the presence of pre-fertilization barriers. We show that these barriers could be partially bypassed by combining pollination with a stigma treatment. More specifically, a significantly higher ratio of the pollen tube length to the total style length and a better seed set were observed when the stigma was treated with the auxin 2,4-dichlorophenoxyacetic acid $\left(2,4-\mathrm{D}, 1 \mathrm{mg} \cdot \mathrm{mL}^{-1}\right)$ together with the cytokinin kinetin (KIN, $0.5 \mathrm{mg} \cdot \mathrm{mL}^{-1}$ ) $24 \mathrm{~h}$ after pollination, irrespective of the cross direction. More specifically, the stigma treatments with any form of auxin (combined or not combined with cytokinin) resulted in a full seed set, assuming an apomictic fruit set, because no pollination was needed to obtain these seeds.
\end{abstract}

Keywords: breeding; geophytes; interspecific cross; plant hormone treatment; pollen-pistil interaction; pre-zygotic barrier; Ranunculaceae

\section{Introduction}

Plant variation is the driving force in ornamental plant cultivation. Crosses between partners with a high genetic distance are important inducers of variation, provided they produce viable seeds. However often incongruity occurs, which can be defined as a mechanism for the common phenomenon of non-functioning of pollen-pistil relationships in interpopulational matings [1]. This is not the same as incompatibility, which is based on a non-recognition system between a male and female determinant ( $S$-locus) [2]. These interpopulational reproductive barriers occur in and can be divided into pre-zygotic (or pre-fertilization) and post-zygotic (or post-fertilization) barriers, depending on the time and place of occurrence [3-7]. Pre-zygotic barriers are observed before fertilization and are mostly situated at the stigmatic surface or in the style, while post-zygotic barriers prevent further embryo development into a plant. The interactions that occur between pollen and stigma/style consist of six key stages: pollen capture and adhesion, pollen hydration, pollen germination, pollen tube penetration, tube growth through the stigma and style, entry of the pollen tube into the ovule, and discharge of the sperm cells [8]. In a successful interaction, all six steps are completed, while, in an incongruous interaction, one or more steps may be hindered preventing fertilization [8]. The stigma type can influence this interaction. Stigmas are divided in dry and wet stigmas depending on the occurrence 
of exudation during stigma receptivity [9]. Pollen rejection is more likely to occur in plant species with dry stigmas, as the secretions on a wet stigma do not discriminate pollen and trap and hydrate all of them [10]. Besides the effect of the stigma type, barriers can limit or obstruct the growth of the pollen tube in the style induced by cytotoxins or cell wall modifying enzymes produced by the female transmitting tissue [10].

In this study, we focus on the pre-zygotic barriers. Although these barriers are efficient and successful to prevent distant crosses in nature, they can be artificially overruled [11]. Pre-zygotic barriers can be bypassed by reciprocal crosses, mixed pollinations (pollination with a combination of incongruent and congruent pollen) or pollinations by mentor pollen (pollination with a combination of incongruent and irradiated congruent pollen with nonfunctional sperm nuclei), style manipulations, crosses at an aberrant flower age or by stigma treatments with different chemical compounds $[7,12,13]$. In the interspecific hybridization of Banksia hookeriana and Banksia prionotes, hybrids were only observed when Banksia hookeriana was used as female parent [14]. Artificial crosses between Diplotaxis siettiana and Brassica juncea are not successful, but when pollen of Diplotaxis siettiana was irradiated with 1000 Gy gamma radiation and was dusted on the stigma, fertilization could occur [15]. Mixed pollinations produced wide hybridizations in blueberry [16] as has style manipulations in Lilium [17]. The flower's age can also have an effect on its receptivity and its pollen reaction. Delayed pollination can overcome self-incompatibility, while a functional incongruity system might be not yet fully established in younger flowers [18]. Compounds that are added at the stigma are based on the composition of exudates that occur at wet stigmas. In wet stigmas, either lipid-rich or carbohydrate-rich compounds occur [8]. In species with dry stigma, such as Anemone coronaria L. and Ranunculus asiaticus L. [19], the pollen kit takes over the function of the exudates, suggesting that sugars or lipids may also be required for pollen tube penetration in species with dry stigmas [20]. The application of growth regulators, such as auxins, cytokinins and gibberellins, to the stigma at the time of, or soon after pollination may improve seed set in distant crosses $[7,21,22]$.

In this study, pollen-stigma interactions were studied in crosses between A. coronaria and $R$. asiaticus. These are both important ornamental species belonging to the Ranunculaceae. The Ranunculaceae are grouped based on chromosome types into Ranunculoideae and Thalictroideae [23]. The subfamily, Ranunculoideae, is ordered in several tribes where the genus Anemone is included within the Anemoneae and Ranunculus within the Ranunculeae, resulting in intertribal cross combinations when crosses are done between both genera. In the present study, pre-zygotic barriers were extensively investigated and protocols to overcome barriers were tested in these genetic distant crosses between $A$. coronaria and R. asiaticus.

\section{Materials and Methods}

\subsection{Plant Material and Growth Conditions}

Three cultivars of Anemone coronaria L. (i.e., 'Mistral Wine', 'Mistral Fucsia' (both Mistral ${ }^{\circledR}$ Line, Biancheri Creations, Camporosso Mare, Italy) and 'Wicabri Blue' (Wicabri ${ }^{\circledR}$ Line, the Netherlands)) were combined according to the availability of receptive flower stages for mating and pollen availability with three cultivars of Ranunculus asiaticus L., ('Alfa' (Vitro Line Success ${ }^{\circledR}$, Biancheri Creations, Camporosso Mare, Italy), 'Krisma' (Istituto Regionale per la Floricoltura, Sanremo, Italy) and 'Bianco Strié' (Biancheri Creations, Camporosso Mare, Italy)). From each cultivar more than 30 plants were available.

Rhizomes were planted in September as followed: tuberous rhizomes were soaked in water for $24 \mathrm{~h}$ at $10{ }^{\circ} \mathrm{C}$ and subsequently planted in a peat mixture $\left(\mathrm{pH}_{\mathrm{H} 2 \mathrm{O}} 6.5-7.5\right)$ with $5 \%$ perlite, $5 \%$ clay and fertilizers (NPK $14-16-18,1 \mathrm{~kg} \mathrm{~m}^{-3}$ ). The soil surface was sprayed with prochloraz (Sporgon ${ }^{\circledR}, 0.6 \mathrm{~g} \mathrm{~L}^{-1}$ ) directly after planting, to prevent root rot by fungi. Standard nursery practices were used for watering, fertilization and pest control [24-26]. Plants were grown in a greenhouse (natural photoperiod regime) with climate condition settings of $18{ }^{\circ} \mathrm{C}$ day temperature and $5{ }^{\circ} \mathrm{C}$ night temperature. During the day ( 8 a.m. -4 p.m.) extra assimilation light was given (assimilation light HPI-T Plus 
Philips, PAR: $25-30 \mu \mathrm{mol} \mathrm{m}{ }^{-2} \mathrm{~s}^{-1}$ ). All plants spontaneously started to flower in the March-April period.

\subsection{Crosses and Observation of Pre-Fertilization Barriers}

Flowers that were used as mother plants were emasculated one day before pollination and protected from surrounding pollen by a paper bag. Pollen was freshly harvested from flowering plants and collected with a brush (one specific brush for each cultivar) in a Petri dish. Pollination (done one time per cross) was achieved by dusting pollen with a brush on the receptive carpels. After pollination, which was done before noon, the flower was packed in a paper bag to prevent other pollinations.

To investigate pre-fertilization barriers for the intertribal and reciprocal crosses between Anemone and Ranunculus, scanning electron microscopy (TM-1000 Tabletop microscope, HITACHI) was combined with aniline blue staining monitored by fluorescence microscopy (Olympus IX81).

Aniline blue staining of the carpels was started $56 \mathrm{~h}$ after pollination. The pollinated carpels (10 to 20 per cross combination) were fixed in FAA (formaldehyde:alcohol (ethanol $70 \%$ ):acetic acid, 1:1:18) for $24 \mathrm{~h}$ and subsequently macerated by $\mathrm{NaOH}(8 \mathrm{M})$ for $16 \mathrm{~h}$. After being thoroughly washed in water, the carpels were stained in a $0.1 \%(w / v)$ aniline blue solution in $0.033 \mathrm{M} \mathrm{K}_{3} \mathrm{PO}_{4}$ for $3 \mathrm{~h}$ in the dark.

\subsection{Techniques to Bypass Pre-Fertilization Barriers}

Undisturbed carpels were treated with one of the following solutions (acronym):

- pollen germination medium $(\mathrm{PM})\left(100 \mathrm{mg} \cdot \mathrm{L}^{-1} \mathrm{H}_{3} \mathrm{BO}_{3}, 700 \mathrm{mg} \cdot \mathrm{L}^{-1} \mathrm{Ca}\left(\mathrm{NO}_{3}\right)_{2} \cdot 4 \mathrm{H}_{2} \mathrm{O}\right.$, $200 \mathrm{mg} \cdot \mathrm{L}^{-1} \mathrm{MgSO}_{4} \cdot 7 \mathrm{H}_{2} \mathrm{O}, 100 \mathrm{mg} \cdot \mathrm{L}^{-1} \mathrm{KNO}_{3}, 150 \mathrm{~g} \cdot \mathrm{L}^{-1}$ PEG 6000, $740 \mathrm{mg} \cdot \mathrm{L}^{-1}$ L-glutamic acid and $100 \mathrm{~g} \cdot \mathrm{L}^{-1}$ sucrose, $\mathrm{pH}$ 6.0), just before pollination;

- $\quad$ sucrose solutions $(5 \%(w / v)$, sucrose), just before pollination;

- $\quad$ salt solution (0.5 M NaCl, salt), just before pollination;

- $\quad$ olive oil (oil), just before pollination;

- $\quad$ auxin 2,4-dichlorophenoxyacetic acid (2,4-D, $\left.1 \mathrm{mg} \cdot \mathrm{mL}^{-1}\right), 24 \mathrm{~h}$ after pollination;

- $\quad$ auxin 1-naphtaleneacetic acid (NAA, $\left.1 \mathrm{mg} \cdot \mathrm{mL}^{-1}\right), 24 \mathrm{~h}$ after pollination;

- gibberellic acid $\left(\mathrm{GA}_{3}, 1 \mathrm{mg} \cdot \mathrm{mL}^{-1}\right), 24 \mathrm{~h}$ after pollination;

- $\quad$ cytokinin kinetin $\left(\mathrm{KIN}, 1 \mathrm{mg} \cdot \mathrm{mL}^{-1}\right), 24 \mathrm{~h}$ after pollination; or

- the combination of 2,4-D (1 mg. $\left.\mathrm{mL}^{-1}\right)$ and KIN $\left(0.5 \mathrm{mg} \cdot \mathrm{mL}^{-1}\right)$ together (Comb), $24 \mathrm{~h}$ after pollination.

Furthermore, other applied techniques were:

- cut-style pollination (SC): $3 / 4$ of the stylar tissue was cut where after the wound was pollinated;

- mentor pollination (mentor): plants were pollinated with a mix of intrageneric pollen (congruent, i.e., R. asiaticus 'Alfa' pollen for Ranunculus $\times$ Anemone) and intertribal pollen but the congruent pollen was irradiated with $2000 \mathrm{~Gy}$ to prevent the formation of viable sperm nuclei;

- $\quad$ mixed pollination (mix): carpels were pollinated with the pollen of the other genus and one to two days later with compatible pollen (of the same cultivar for Anemone or with 'Bianco Strié' for Ranunculus);

- $\quad$ use of rehydrated pollen (2 $\mathrm{h}$ in a fog tunnel prior to pollination) (RV);

- pollination of old, emasculated flowers (old, carpels 3-6 days after anthesis for Anemone and 4-10 days after anthesis for Ranunculus); and

- pollination of young, emasculated flowers (young, 5 to 8 days before anthesis).

Aniline blue staining was used in part of the crosses to check if the pre-zygotic barriers had been bypassed (number of crosses per treatment and per cross direction, see Table 2) and part of the crosses was left untouched to determine the seed formation and the success rate of the manipulations (number of crosses per treatment and per cross direction, see Table 3). 


\subsection{Flow Cytometry of Fruitlets}

Leaf tissue (standard), green fully developed fruitlets, obtained after self-pollination (standard); fruitlets, obtained after 2,4-D treatment $\left(1 \mathrm{mg} \cdot \mathrm{mL}^{-1}\right)$ without pollination + packed in a paper bag; and fruitlets, obtained after stigma treatment with 2,4-D $\left(1 \mathrm{mg} \cdot \mathrm{mL}^{-1}, 24 \mathrm{~h}\right.$ post-pollination with compatible pollen) from Anemone 'Wicabri Blue', were used for flow cytometry. These fruitlets were peeled and subsequently chopped with a sharp razor blade in $250 \mu \mathrm{L}$ 0.1-M citric acid monohydrate and $0.5 \%$ Tween ${ }^{\circledR}$ according to Galbraith et al. [27]. Subsequently, the samples were filtered (pore size $100 \mu \mathrm{m}$ ). The filter was washed by adding $500 \mu \mathrm{L}$ staining solution with $0.4 \mathrm{M} \mathrm{Na}_{2} \mathrm{HPO}_{4} \cdot 12 \mathrm{H}_{2} \mathrm{O}$ and $2 \mathrm{mg} \cdot \mathrm{L}^{-1} 4^{\prime}, 6$-diamidino2-phenylindole (DAPI) [28]. The relative fluorescence of the total DNA of a single nuclei was analyzed using a flow cytometer equipped with a mercury lamp (Partec PAS III). At least ten fruitlets per case were analyzed. For the analysis of leaf material, at least 3000 nuclei were counted; in the case of fruitlets, the number of nuclei was lower (min. 1000 nuclei) due to the lesser amount of cells in the individual seeds.

\subsection{Statistics}

The ratio pollen tube length/total style length was evaluated by analysis of variance with the statistical program SPSS Statistics 26.0. A two-tailed Dunnett's test was done as a post-hoc test on a one-way ANOVA in which the stigma treatments and pollination techniques were compared to the control cross.

\section{Results}

Pollen-stigma interaction in the intertribal crosses between A. coronaria and R. asiaticus was regular, as pollen adhesion and hydration, followed by germination and pollen tube penetration, could be clearly observed (Figure 1).

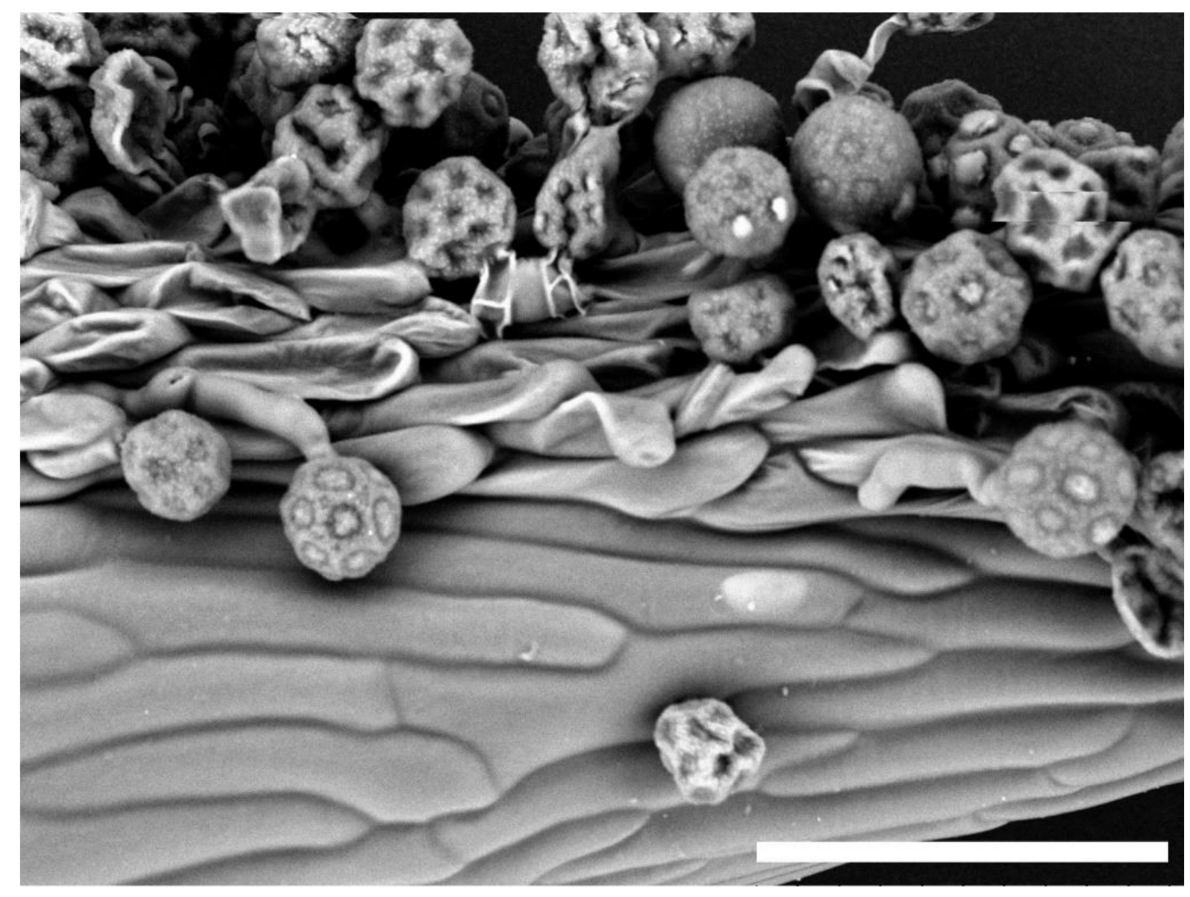

Figure 1. Scanning electron microscopy of stigmatic papillae of R. asiaticus 'Alfa' which was pollinated with A. coronaria 'Mistral Wine' (bar $=100 \mu \mathrm{m})$.

Despite this normal pollen-stigma event, pollen tubes mostly did not reach the ovules. However, using Anemone as a mother plant resulted in higher ratios of the pollen tube length to the total style length compared with the reciprocal crosses, except for $R$. 'Alfa' $\times$ A. 'Mistral Wine' (Table 1). 
Table 1. Ratio of the pollen tube length to the total style length in intertribal crosses between $A$. coronaria and $R$. asiaticus, visualized by aniline blue staining $56 \mathrm{~h}$ after pollination (mean $\pm \mathrm{SE}$ ( $\mathrm{n}=$ number of repetitions)).

\begin{tabular}{|c|c|c|}
\hline Mother Plant & Male Plant & $\begin{array}{l}\text { Pollen Tube Length/ } \\
\text { Total Style Length (n) }\end{array}$ \\
\hline \multirow{3}{*}{ A. 'Mistral Fucsia' } & $R$. 'Alfa' & $0.229 \pm 0.064(27)$ \\
\hline & R. 'Krisma' & $0.649 \pm 0.141(10)$ \\
\hline & R. 'Bianco Strié' & $0.175 \pm 0.035(20)$ \\
\hline \multirow{3}{*}{ A. 'Mistral Wine' } & $R$. 'Alfa' & $0.194 \pm 0.044(27)$ \\
\hline & R. 'Krisma' & $0.385 \pm 0.068(10)$ \\
\hline & R. 'Bianco Strié' & $0.391 \pm 0.081(11)$ \\
\hline \multirow{3}{*}{ A. 'Wicabri Blue' } & $R$. 'Alfa' & $0.203 \pm 0.040(19)$ \\
\hline & R. 'Krisma' & $0.133 \pm 0.021(20)$ \\
\hline & R. 'Bianco Strié' & $0.118 \pm 0.017(20)$ \\
\hline \multirow{3}{*}{ R. 'Alfa' } & A. 'Mistral Fucsia' & $0.168 \pm 0.026(37)$ \\
\hline & A. 'Mistral Wine' & $0.261 \pm 0.041(15)$ \\
\hline & A. 'Wicabri Blue' & $0.159 \pm 0.029$ \\
\hline \multirow{3}{*}{ R. 'Krisma' } & A. 'Mistral Fucsia' & $0.182 \pm 0.032(27)$ \\
\hline & A. 'Mistral Wine' & $0.068 \pm 0.012$ \\
\hline & A. 'Wicabri Blue' & $0.036 \pm 0.005(19)$ \\
\hline \multirow{3}{*}{ R. 'Bianco Strié' } & A. 'Mistral Fucsia' & $0.042 \pm 0.005(19)$ \\
\hline & A. 'Mistral Wine' & $0.057 \pm 0.009$ (19) \\
\hline & A. 'Wicabri Blue' & $0.046 \pm 0.006(19)$ \\
\hline
\end{tabular}

Compared to self-pollinations, the intertribal crosses caused an inhibition of the growth in the style, visualized by abnormalities like coiled and spirally twisted pollen tubes, disorientation of pollen tubes and a higher level of deposition of callose plugs (densely illuminated regions) (Figure 2).
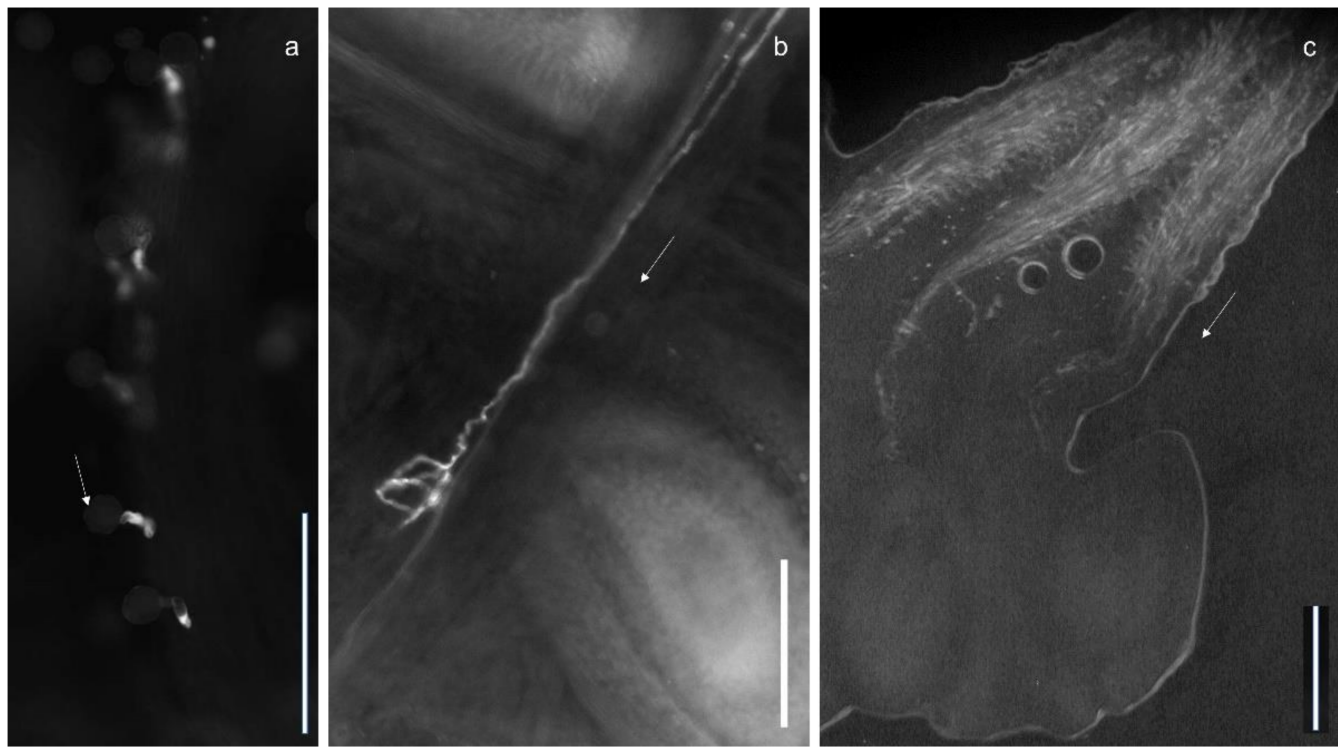

Figure 2. Aniline blue staining of intertribal crosses between (a) R. asiaticus 'Bianco Strié' $\times A$. coronaria 'Mistral Fucsia' showing very short pollen tubes and (b) A. coronaria 'Mistral Wine' $\times R$. asiaticus 'Krisma' with a pollen tube with abnormal coils. (c) An aniline blue staining of self-pollinated A. coronaria 'Wicabri Blue' carpels showing pollen tubes reaching the ovules (bar $=0.2 \mathrm{~mm}$ ). The arrow shows the direction to the ovules. 
Compared to the untreated stigmas, the combined treatment of the stigma with 2,4-D together with KIN (Comb) $24 \mathrm{~h}$ after pollination resulted in a significant increase in the ratio of the pollen tube length to the total style length (Table 2), both in the Ranunculus $\times$ Anemone cross and its reciprocal. When treating an Anemone stigma $24 \mathrm{~h}$ post-pollination with 2,4-D or NAA alone, a longer pollen tube length was noticed in the crosses of Anemone $\times$ Ranunculus compared to the untreated cross. Some ratios of the pollen tube length to total style length were negatively affected by the treatments. This was the case for the use of pollen germination medium (PM), cut style method (SC) and mentor pollination for the cross Ranunculus $\times$ Anemone, while, in the reciprocal cross, only the application of oil had a negative effect, resulting in no pollen tube growth at all (Table 2).

Table 2. Ratio of the pollen tube length to the total style length, visualized by aniline blue staining of the intertribal crosses Ranunculus $\times$ Anemone and the reciprocal cross thereof using different treatments and techniques to overcome pre-fertilization barriers $(\mathrm{PM}=$ pollen medium, sucrose $=5 \%(w / v)$ sucrose solution, salt $=0.5 \mathrm{M} \mathrm{NaCl}$, oil $=$ olive oil, $\mathrm{comb}=2,4-\mathrm{D}+\mathrm{KIN} 24 \mathrm{~h}$ after pollination, SC = cut-style pollination, mentor = mentor pollination, $\operatorname{mix}=$ mixed pollination, $\mathrm{RV}=$ pollen rehydration, old $=$ an older flower stage than the reference flower stage, young = a younger flower stage than the reference stage) (mean $\pm \mathrm{SE})$. ( $\mathrm{n}=$ number of crosses).

\begin{tabular}{|c|c|c|c|c|c|c|}
\hline \multirow[b]{2}{*}{$\begin{array}{l}\text { Treatment/ } \\
\text { Technique }\end{array}$} & \multicolumn{3}{|c|}{ Ranunculus $\times$ Anemone } & \multicolumn{3}{|c|}{ Anemone $\times$ Ranunculus } \\
\hline & $\mathbf{n}$ & $\begin{array}{l}\text { Pollen Tube } \\
\text { Length/Total } \\
\text { Style Length }\end{array}$ & Test Cross & $\mathbf{n}$ & $\begin{array}{l}\text { Pollen Tube } \\
\text { Length/Total } \\
\text { Style Length }\end{array}$ & Test Cross \\
\hline PM & 11 & $0.026 \pm 0.005 * \mathrm{y}$ & 'Alfa' $\times$ 'Mistral Wine' & 9 & $0.302 \pm 0.064$ & 'Wicabri Blue' × 'Alfa' \\
\hline sucrose & 8 & $0.136 \pm 0.029$ & 'Alfa' $\times$ 'Mistral Wine' & 5 & $0.559 \pm 0.096$ & 'Mistral Fucsia' $\times$ 'Alfa' \\
\hline salt & 12 & $0.159 \pm 0.028$ & 'Alfa' $\times$ 'Mistral Wine' & 5 & $0.143 \pm 0.035$ & 'Mistral Fucsia' × 'Bianco Strié' \\
\hline oil & 20 & $0.292 \pm 0.054$ & 'Alfa' × 'Mistral Wine' & 10 & $0.000 \pm 0.000 * \mathrm{y}$ & 'Mistral Wine' $\times$ 'Bianco Strié' \\
\hline $2,4-\mathrm{D}$ & 6 & $0.078 \pm 0.008$ & 'Alfa' $\times$ 'Mistral Fucsia' & 7 & $0.529 \pm 0.164 *$ & 'Wicabri Blue' × 'Alfa' \\
\hline NAA & 4 & $0.112 \pm 0.062$ & 'Alfa' × 'Mistral Fucsia' & 5 & $0.681 \pm 0.155^{*}$ & 'Mistral Fucsia' × 'Alfa' \\
\hline $\mathrm{GA}_{3}$ & 10 & $0.200 \pm 0.055$ & 'Alfa' $\times$ 'Mistral Fucsia' & 4 & $0.490 \pm 0.135$ & 'Mistral Fucsia' $\times$ 'Alfa' \\
\hline KIN & 7 & $0.169 \pm 0.060$ & 'Alfa' × 'Mistral Fucsia' & 6 & $0.258 \pm 0.106$ & 'Mistral Wine' $\times$ 'Bianco Strié' \\
\hline comb & 9 & $0.423 \pm 0.121 *$ & 'Alfa' $\times$ 'Mistral Fucsia' & 4 & $0.505 \pm 0.096^{*}$ & 'Mistral Fucsia' × 'Bianco Strié' \\
\hline SC & 10 & $0.000 \pm 0.000 *$ & 'Alfa' × 'Mistral Wine' & 6 & $0.199 \pm 0.025$ & 'Wicabri Blue' $\times$ 'Alfa' \\
\hline mentor & 9 & $0.038 \pm 0.018 *$ & 'Krisma' $\times$ 'Mistral Fucsia' & 0 & - & - \\
\hline $\operatorname{mix}$ & $0^{z}$ & - & - & $0^{\mathrm{z}}$ & - & - \\
\hline RV & 16 & $0.189 \pm 0.044$ & 'Alfa' $\times$ 'Mistral Wine' & 5 & $0.439 \pm 0.212$ & 'Mistral Wine' $\times$ 'Alfa' \\
\hline old & 7 & $0.070 \pm 0.012$ & 'Alfa' $\times$ 'Mistral Fucsia' & 6 & $0.066 \pm 0.018$ & 'Mistral Fucsia' $\times$ 'Alfa' \\
\hline young & 7 & $0.103 \pm 0.029$ & 'Alfa' $\times$ 'Mistral Fucsia' & 5 & $0.439 \pm 0.069$ & 'Mistral Wine' $\times$ 'Alfa' \\
\hline
\end{tabular}

${ }^{\mathrm{z}}$ Aniline blue staining was not conducted for the mixed pollination, because pollen could not be distinguished. ${ }^{\mathrm{y}}$ Dunnett's $t$ test (two-sided, $p \leq 0.05)$, * means significant different compared to reference control cross done during the same time period (see Table 1), each test cross was analyzed separately.

Although an increased ratio of pollen tube length to total style length of some of these treatments and techniques was observed, sometimes the pollen tubes showed aberrant orientations (Figure 3). Often, highly twisted pollen tubes were observed with callose plugs (Figure $3 a, c, d, g)$.

The positive effect of the application of auxin (2,4-D, NAA), alone or in combination with KIN (Comb) $24 \mathrm{~h}$ post-pollination, resulted in a normal seed set, both in Anemone $\times$ Ranunculus crosses and their reciprocals (Table 3). This was also the case when the 2,4-D was applied $24 \mathrm{~h}$ before pollination (data not shown) and when mixed pollination was applied. In contrast to auxin, $\mathrm{KIN}, \mathrm{GA}_{3}$ and mentor pollination did not result in a complete seed set, but they slightly enhanced fruitlet formation in the Ranunculus $\times$ Anemone cross but not in the reciprocal cross (Table 3). Application of other components to the carpels or pollination techniques did not improve seed set substantially (Table 3). The treatment of the carpels with pollen germination medium or sugar resulted often in a dehydrated thalamus not able to bear any fruitlets. 


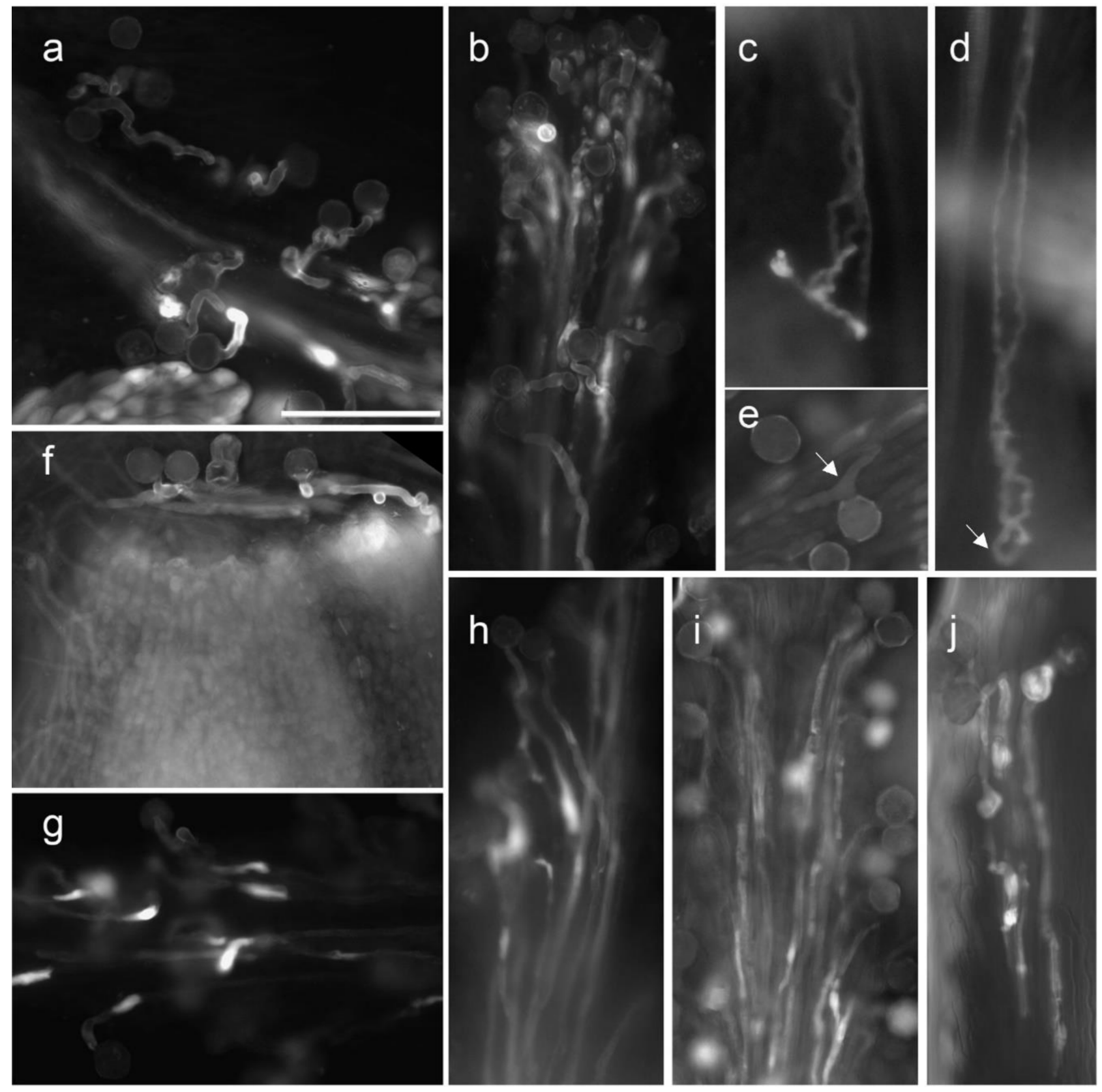

Figure 3. Aniline blue staining of intertribal crosses between A. coronaria and R. asiaticus using different treatments and techniques to overcome pre-zygotic barriers (bar $=0.125 \mathrm{~mm}$ ). (a) Spirally growth of pollen tubes with many callose plugs (intense illuminated regions) were observed when the pollen germination medium (PM) was sprayed on the stigma before pollination $(A$. 'Wicabri Blue' $\times R$. 'Alfa'). (b) Pollen tube growth in a cross of $A$. 'Wicabri Blue' $\times R$. 'Alfa' after a 2,4-D treatment. (c,d) A relative long pollen tube of $R$. 'Alfa' in the style of $A$. 'Mistral Fucsia' after a NAA treatment, but when the pollen tube came near to the ovule a loop (see arrow) was formed and the pollen tube was totally disoriented. (e) In the cross of 'Mistral Fucsia' $\times$ 'Alfa' a branched pollen tube (see arrow) was observed when older carpels were pollinated. (f) Cut-style pollination resulted in pollen tube growth but with only slight penetration in the style ('Wicabri Blue' $\times$ 'Alfa'). (g) Young, pollinated carpels showed many callose plugs ('Mistral Wine' $\times$ 'Alfa'). (h) GA 3 treatment gave a relative normal pollen tube growth in 'Mistral Fucsia' $\times$ 'Alfa'. (i) Pollen tube growth of 'Bianco Strié' in the style, after a 2,4-D and KIN treatment (comb) of carpels, of 'Mistral Fucsia'. (j) Pollen tube growth of 'Mistral Fucsia' in the style, after a 2,4-D and KIN treatment (comb), of 'Alfa' carpels. 
Table 3. Number (\#) of intertribal crosses, total number (\#) of fruitlets and the ratio of the total number (\#) of fruitlets on the total number (\#) of crosses between Ranunculus $\times$ Anemone and their reciprocal crosses, using different treatments and techniques to overcome pre-zygotic barriers ( $\mathrm{PM}=$ pollen medium, sucrose $=5 \%(\mathrm{w} / \mathrm{v})$ sucrose solution, salt $=0.5 \mathrm{M}$ $\mathrm{NaCl}$, oil = olive oil, comb = 2,4-D + KIN $24 \mathrm{~h}$ after pollination, $\mathrm{SC}=$ cut-style pollination, mentor = mentor pollination, $\operatorname{mix}=$ mixed pollination, $\mathrm{RV}=$ pollen rehydration, $\mathrm{old}=\mathrm{an}$ older flower stage than the reference flower stage, Young $=\mathrm{a}$ younger flower stage than the reference stage).

\begin{tabular}{|c|c|c|c|c|c|c|}
\hline \multirow{2}{*}{$\begin{array}{l}\text { Treatment/ } \\
\text { Technique }\end{array}$} & \multicolumn{3}{|c|}{ Ranunculus $\times$ Anemone } & \multicolumn{3}{|c|}{ Anemone $\times$ Ranunculus } \\
\hline & \# Crosses & \# Fruitlets & \# Fruitlets/\# Cross & \# Crosses & \# Fruitlets & \# Fruitlets/\# Cross \\
\hline control & 149 & 96 & 0.6 & 44 & 136 & 3.1 \\
\hline PM & 58 & 9 & 0.2 & 1 & 0 & 0.0 \\
\hline sugar & 43 & 10 & 0.2 & 0 & - & - \\
\hline salt & 43 & 9 & 0.2 & 0 & - & - \\
\hline oil & 60 & 19 & 0.3 & 4 & 1 & 0.3 \\
\hline $2,4-\mathrm{D}$ & 75 & 3760 & 50.1 & 8 & 630 & 78.8 \\
\hline NAA & 43 & 2657 & 61.8 & 6 & 210 & 35.0 \\
\hline $\mathrm{GA}_{3}$ & 45 & 57 & 1.3 & 7 & 4 & 0.6 \\
\hline KIN & 48 & 118 & 2.5 & 3 & 1 & 0.3 \\
\hline comb & 42 & 2697 & 64.2 & 12 & 588 & 49.0 \\
\hline SC & 20 & 4 & 0.2 & 3 & 3 & 1.0 \\
\hline mentor & 5 & 8 & 1.6 & 0 & - & - \\
\hline $\operatorname{mix}$ & 20 & 858 & 42.9 & 15 & 582 & 38.8 \\
\hline RV & 30 & 15 & 0.5 & 9 & 31 & 3.4 \\
\hline old & 64 & 4 & 0.1 & 5 & 2 & 0.4 \\
\hline young & 6 & 4 & 0.7 & 0 & - & - \\
\hline
\end{tabular}

To investigate more into detail the visual observation that 2,4-D resulted in a good seed set in our intertribal crosses (Table 3), carpels of emasculated flowers were treated with 2,4-D without pollination. To our surprise, seed set occurred (Figure 4). Therefore, flow cytometry was used to compare leaf tissue and obtained fruitlets by self-pollination (control fruitlets) with fruitlets received after a 2,4-D treatment without pollination. Leaf tissue of 'Wicabri Blue' resulted in a clear diploid ploidy level $(2 \times)$ and control peeled fruitlets had a dominant $2 \times$ peak (embryo and seed coat) and a small $3 \times$ peak (endosperm) (Figure 5a,b). Peeled fruitlets of 'Wicabri Blue' obtained after 2,4-D treatment without pollination resulted in a dominant $2 \times$ peak (Figure 5 c) with occasionally a very small $4 \times$ peak, no $3 \times$ peak was visible, suggesting a lack of endosperm. These results, together with the abortion of the seed at maturation (data not shown) let us postulate the hypothesis that 2,4-D promotes apomixis, giving a $2 \times$ maternal embryo and a very limited or even no development of endosperm-like tissue. To complete this study, 2,4-D treated carpels were pollinated $24 \mathrm{~h}$ after treatment with pollen (self-pollination): most of the fruitlets $(8 / 11) \mathrm{did}$ not show a $3 \times$ peak, while some $(3 / 11)$ showed a $2 \times$ and $3 \times$ peak (Figure $5 \mathrm{~d})$. Probably, the latter were fruitlets from sexual fertilizations.

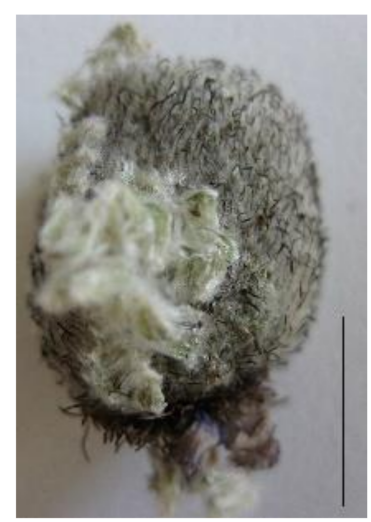

Figure 4. Fruitlets of A. coronaria 'Wicabri Blue' after treatment of unpollinated carpels with 2,4-D (bar $=1 \mathrm{~cm})$. 

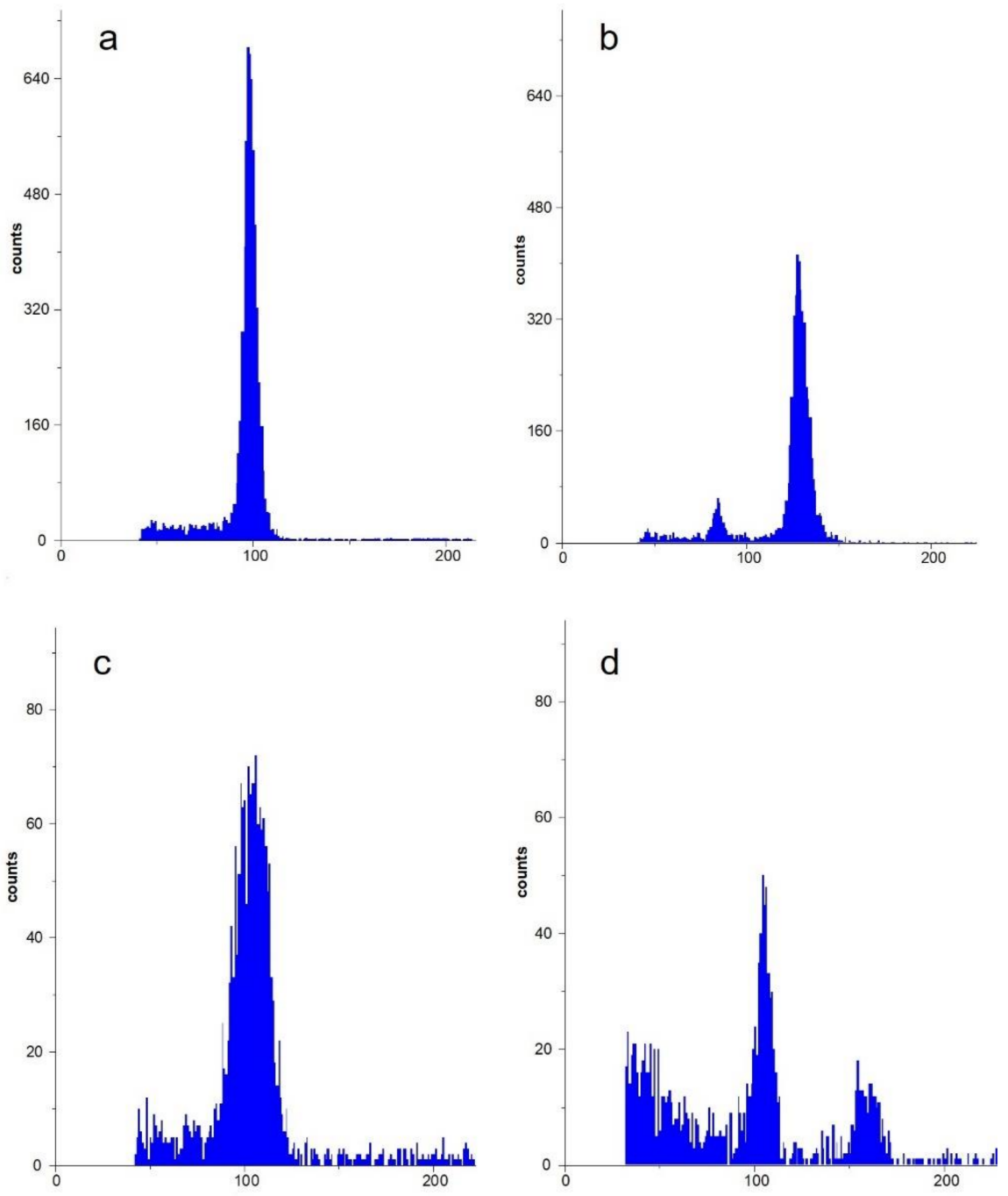

Figure 5. Flow cytometry of $A$. coronaria 'Wicabri Blue'. (a) Flow cytometric pattern of leaf tissue of $A$. coronaria 'Wicabri Blue', the $2 \times$ peak was set at 100 . (b) Flow cytometric analysis of mature fruitlets of self-pollinated 'Wicabri Blue' as control, showing a diploid ploidy level (embryo and seed coat) and a triploid ploidy level (endosperm). (c) Flow cytometric analysis of immature fruitlets obtained from unpollinated 2,4-D treated carpels, showing a $2 \times$ peak (embryo, seed coat). (d) Flow cytometric analysis of immature fruitlets obtained from self-pollinated 2,4-D treated carpels. The pollination was done $24 \mathrm{~h}$ after 2,4-D treatment. A minority (3/11) showed a $2 \times$ peak (embryo, seed coat) and a $3 \times$ peak (endosperm), probably the result of a sexual fertilization. The majority had the same pattern as shown in (c).

\section{Discussion}

Unilateral incongruity is a phenomenon often observed in distant crosses. It means that a cross is successful in one direction, whereas the reciprocal cross fails [7]. In the intertribal crosses between A. coronaria and R. asiaticus, the Anemone $\times$ Ranunculus cross clearly resulted in higher ratios of pollen tube lengths to total style lengths than had the reciprocal cross. Some studies demonstrated a correlation between self-incompatibility and unilateral preference: pollen from self-compatible species is often rejected by selfincompatible species, whereas the reciprocal crosses are viable [6,12,29-31]. This was confirmed by interspecific crosses of Banksia hookeriana and Banksia prionotes, where seed set was only observed in Banksia hookeriana and in which Banksia prionotes showed signs of a late self-incompatibility [14]. This may partially explain the lower pollen tube to the total style length ratios of Ranunculus $\times$ Anemone because of the self-incompatible nature of the Ranunculus cultivar 'Alfa' [19]. Besides the pollen tube inhibition observed in both 
cross directions, pollen tubes also showed abnormalities such as disoriented, coiled and twisted pollen tubes with many callose plugs. Similar phenomena were observed in other interspecific crosses involving cotton and some wild relatives [22,32] and in intergeneric crosses in the Bromeliaceae family [33].

In Anemone and Ranunculus, the stigma is typically dry papillated [19]. As dry stigmas do not produce exudates, pollen adhesion is largely realized by the properties of the pollen surface [34]. Adhesion relies on the interaction between pollen coat proteins and receptors in the stigma [10]. After adhesion, mobilization of the pollen kit occurs, leading to the mixing of lipids and proteins to form a 'foot' of contact on the stigma surface [35]. This appressorium-like 'foot' appears to glue the pollen to the stigma, after which hydration takes place [8,20]. In Arabidopsis, it has been shown that the strength of pollen adhesion is directly proportional to the genetic distance between species [34]. In our intertribal crosses, this pollen-pistil interaction was showing no abnormalities, resulting in pollen adhesion, hydration, germination and pollen tube penetration into the stylar tissue. In several distant crosses, stigma treatments have shown their effectiveness to stimulate pollen hydration and germination. The treatment of female flowers of Carica papaya with $5 \%$ sucrose before pollination with the wild species Vasconcellea cauliflora enhanced the pollen germination and pollen tube growth [36]. On the other hand, in tobacco, the presence of cis-unsaturated triacylglycerides on the stigma has been shown to be essential and sufficient for pollen hydration, germination and penetration of the tubes into the pistil [20,37]. Olive oil (rich in cis-unsaturated triacylglycerides), pollen germination medium (sugar-rich) and sugar solutions were not very supportive in the crosses between Anemone and Ranunculus. Most probably, this is because the intertribal crosses showed no inhibition of pollen adhesion, hydration or germination. The time needed for rehydration of the pollen varies significantly between species [37] and many pollen germination percentages could be increased if pollen grains were equilibrated in a moisture environment before pollination [38,39]. Therefore, artificial pollen rehydration prior to pollination was applied in our intertribal crosses of Anemone and Ranunculus. However, without any significant effect. The system of selfincompatibility did not act in the same way as the incongruity system in wide crosses, but often similar techniques are used to overcome them. As the efficient application of saline solutions $(0.25-1 \mathrm{M})$ to the stigma of Brassica oleracea, $30 \mathrm{~min}$ before pollination, inactivates the self-incompatibility barrier [18], this practice was also tested for our intertribal crosses. However, this technique was not promising. Similarly, flower age, which can have an effect on overcoming self-incompatibility [18], did not ameliorate pollen tube growth in the style compared to control crosses in our intertribal crosses.

The application of plant hormones, such as auxins, cytokinins and gibberellins, impacted the pollen tube growth or seed set in our crosses. More specifically, the combination of 2,4-D and KIN resulted in both a significant increase in pollen tube length, irrespectively of the cross direction, and a complete seed-set. The latter was also the case when the auxins 2,4-D and NAA were used alone. In interspecific hybridization in Lens, the application of $\mathrm{GA}_{3}$ after fertilization increased the percentage of ovules obtained per cross, but the ovules started to turn brown and fruits dried [40]. The auxin 2,4-D is often applied in wide crosses in cereals to stimulate embryo development [41,42] and, in interspecific crosses of Solanum, treatment with 2,4-D on flowers after pollination improved seed set [12]. Notwithstanding 2,4-D having prevented the degeneration of the ovules and promoted the number of developing embryos, apomictic embryos were reported in some grasses and cereals after treatment with 2,4-D [21,43]. These observations are very similar to those obtained in this study. As 2,4-D-treated and pollinated carpels ( $24 \mathrm{~h}$ before or $24 \mathrm{~h}$ after pollination) resulted in a similar full seed set compared with unpollinated 2,4-D-treated carpels, it argues for an apomictic origin of the seeds. Moreover, flow cytometry on fruitlets obtained from unpollinated 2,4-D treated plants revealed a $2 \times$ and, occasionally, a minimal $4 \times$ peak. The $2 \times$ ploidy level is most likely derived from the apomictic embryo (and seed coat), while the absence of a $3 \times$ ploidy level can be explained by an incorrect endosperm balance number, probably triggering seed abortion. In many apomictic plants, the egg 
cell begins to divide autonomously but endosperm formation often requires fertilization (pseudogamy) [44]. This could explain the abortion of these obtained seeds at maturation.

In this study, a broad range of techniques to overcome pre-zygotic barriers was used. Many of them have been successfully applied in other breeding programs. Style manipulations, such as cut-style pollination or the stylar graft technique, in which pollen is deposited on a compatible stigma, after which the upper part of the style is cut and positioned or grafted on another plant, are methods to circumvent stylar and stigmatic barriers, which can prohibit pollen tube growth [7]. Despite its success in Lilium [17], in the intertribal crosses of Anemone and Ranunculus, these style manipulation techniques were technically difficult to implement because of limited style length and they were of very limited success. Another technique used to overcome pre-fertilization barriers is the use of irradiated mentor pollen or mixed pollinations. The reasons for the positive effects of mentor and mixed pollination is still unknown [10]. It has been previously suggested that a high density of pollen grains induces favorable changes in the stigmatic surface and the style [45], while others proposed that congruent pollen can induce hydration and germination of normally incongruent pollen [8]. Mentor and mixed pollination techniques were both promising in some of the intertribal crosses studied here. Mixed pollinations seemed to result in a complete seed set. However, due to the relatively long period of receptivity of the stigma, it is most likely that the formed fruitlets were the result of crosses with the intrageneric pollen.

\section{Conclusions}

A significant effect on seed set of the use of the plant hormone auxin 2,4-D (and NAA), alone or in combination with KIN to bypass breeding barriers in intertribal crosses between Anemone coronaria and Ranunculus asiaticus, was shown in this study. Moreover, 2,4-D and KIN resulted in a significant increase in pollen tube length, irrespectively of the cross direction. However, the use of auxin can probably result in an apomictic seed set, therefore, screening of the progeny is of outmost importance.

This study shows that there are opportunities for breeding programs with genetically distant plant combinations within the Anemoneae and the Ranunculeae tribe by using stigma treatments. Treatments are, however, very cross-specific and must be elucidated empirically.

Author Contributions: Conceptualization, E.D., D.R. and M.-C.V.L.; methodology, E.D.; validation, E.D. and M.-C.V.L.; formal analysis, E.D.; investigation, E.D.; resources, D.R. and M.-C.V.L.; data curation, E.D., D.R. and M.-C.V.L.; writing—original draft preparation, E.D.; writing-review and editing, E.D., D.R. and M.-C.V.L.; visualization, E.D.; supervision, D.R. and M.-C.V.L. All authors have read and agreed to the published version of the manuscript.

Funding: This research received no external funding.

Institutional Review Board Statement: Not applicable.

Data Availability Statement: Raw data were generated at UGent. Derived data supporting the findings of this study are available from the corresponding author [E.D.] on request.

Acknowledgments: The authors thank A. Pennewaert, T. Versluys and C. Petit for their technical assistance, IRF (Istituto Regionale per la Floricoltura, Sanremo, Italy) and Biancheri Creations (Camporosso Mare, Italy) for delivering high-quality plant material and L. Van Hoorebeke and P. Vanderniepen, from the Department of Subatomic and Radiation Physics (Ghent University), for the pollen radiations. L. Leus is thanked for the flow cytometric measurements.

Conflicts of Interest: The authors declare no conflict of interest. The funders had no role in the design of the study; in the collection, analyses or interpretation of data; in the writing of the manuscript or in the decision to publish the results.

\section{References}

1. Hogenboom, N.G. A model for incongruity in intimate partner relationships. Euphytica 1973, 22, 219-233. [CrossRef]

2. Takayama, S.; Isogai, A. Self-Incompatibility in Plants. Annu. Rev. Plant Biol. 2005, 56, 467-489. [CrossRef] 
3. Bhojwani, S.S.; Raste, A.P. In Vitro pollination and fertilization. In In Vitro Haploid Production in Higher Plants; Springer: Dordrecht, The Netherlands, 1996; pp. 237-262.

4. Orr, H.A.; Presgraves, D.C. Speciation by postzygotic isolation: Forces, genes and molecules. BioEssays 2000, 22, 1085-1094. [CrossRef]

5. Bino, R.J.; Van Creij, M.G.M.; Van Der Leede-Plegt, L.M.; Van Tunen, A.J.; Van Tuyl, J.M. Application of in Vitro Pollination and Fertilization Techniques for Breeding and Genetic Manipulation of Lilium. In Sexual Plant Reproduction; Springer: Singapore, 1992; pp. 127-134.

6. Rieseberg, L.H.; Carney, S.E. Plant hybridization. New Phytol. 1998, 140, 599-624. [CrossRef] [PubMed]

7. van Tuyl, J.M.; de Jeu, M.J. Methods for overcoming interspecific crossing barriers. Pollen Biotechnol. Crop Prod. Improv. 1997, 273-292. [CrossRef]

8. Hiscock, S.J.; Allen, A.M. Diverse cell signalling pathways regulate pollen-stigma interactions: The search for consensus. New Phytol. 2008, 179, 286-317. [CrossRef]

9. Heslop-Harrison, Y.; Shivanna, K.R. The Receptive Surface of the Angiosperm Stigma. Ann. Bot. 1977, 41, 1233-1258. [CrossRef]

10. Broz, A.K.; Bedinger, P.A. Pollen-Pistil Interactions as Reproductive Barriers. Annu. Rev. Plant Biol. 2021, 72, 615-639. [CrossRef]

11. Sharma, H.C. How wide can a wide cross be? Euphytica 1995, 82, 43-64. [CrossRef]

12. Jansky, S. Overcoming hybridization barriers in potato. Plant Breed. 2006, 125, 1-12. [CrossRef]

13. Van Tuyl, J.; Lim, K.-B. Interspecific hybridisation and polyploidisation as tools in ornamental plant breeding. Acta Hortic. 2003, 612, 13-22. [CrossRef]

14. Sedgley, M.; Wirthensohn, M.; Delaporte, K.L. Interspecific Hybridization between Banksia hookeriana Meisn. and Banksia prionotes Lindl. (Proteaceae). Int. J. Plant Sci. 1996, 157, 638-643. [CrossRef]

15. Sarmah, B.K.; Sarla, N. Overcoming prefertilization barriers in the cross Diplotaxis siettiana $\times$ Brassica juncea using irradiated mentor pollen. Biol. Plant. 1995, 37, 329-334.

16. Wenslaff, T.F.; Lyrene, P.M. The Use of Mentor Pollination to Facilitate Wide Hybridization in Blueberry. HortScience 2000, 35, 114-115. [CrossRef]

17. Van Tuyl, J.; Van Diën, M.; Van Creij, M.; Van Kleinwee, T.; Franken, J.; Bino, R. Application of in vitro pollination, ovary culture, ovule culture and embryo rescue for overcoming incongruity barriers in interspecific Lilium crosses. Plant Sci. 1991, 74, 115-126. [CrossRef]

18. Carafa, A.M.; Carratù, G. Stigma treatment with saline solutions: A new method to overcome self-incompatibility in Brassica oleracea L. J. Hortic. Sci. 1997, 72, 531-535. [CrossRef]

19. Dhooghe, E.; Grunewald, W.; Reheul, D.; Goetghebeur, P.; Van Labeke, M.-C. Floral characteristics and gametophyte development of Anemone coronaria L. and Ranunculus asiaticus L. (Ranunculaceae). Sci. Hortic. 2012, 138, 73-80. [CrossRef]

20. Wolters-Arts, M.; Lush, W.M.; Mariani, C. Lipids are required for directional pollen-tube growth. Nat. Cell Biol. 1998, 392, 818-821. [CrossRef]

21. Matzk, F. A novel approach to differentiated embryos in the absence of endosperm. Sex. Plant Reprod. 1991, 4, 88-94. [CrossRef]

22. Ram, S.G.; Ramakrishnan, S.H.; Thiruvengadam, V.; Bapu, J.R.K. Prefertilization barriers to interspecific hybridization involving Gossypium hirsutum and four diploid wild species. Plant Breed. 2008, 127, 295-300. [CrossRef]

23. Langlet, O.F.J. Uber Chromosomen Verhaltnisse und Systematik der Ranunculaceae. Sven. Bot. Tidskr. 1932, 26, 318-400.

24. Beruto, M.; Fibiani, M.; Rinino, S.; Scalzo, R.L.; Curir, P. Plant development of Ranunculus asiaticus L. tuberous roots is affected by different temperature and oxygen conditions during storage period. Isr. J. Plant Sci. 2009, 57, 377-388. [CrossRef]

25. Meynet, J. Anemone. In The Physiology of Flower Bulbs; De Hertogh, A., Le Nard, M., Eds.; Elsevier: Amsterdam, The Netherlands, 1993; pp. 211-218.

26. Meynet, J. Ranunculus. In The Physiology of Flower Bulbs; De Hertogh, A., Le Nard, M., Eds.; Elsevier: Amsterdam, The Netherlands, 1993; pp. 603-610.

27. Galbraith, D.W.; Harkins, K.R.; Maddox, J.M.; Ayres, N.M.; Sharma, D.P.; Firoozabady, E. Rapid Flow Cytometric Analysis of the Cell Cycle in Intact Plant Tissues. Science 1983, 220, 1049-1051. [CrossRef] [PubMed]

28. Otto, F. Chapter 11 DAPI Staining of Fixed Cells for High-Resolution Flow Cytometry of Nuclear DNA. In Methods in Cell Biology; Elsevier: Amsterdam, The Netherlands, 1990; Volume 33, pp. 105-110.

29. Lee, C.B.; Page, L.E.; McClure, B.A.; Holtsford, T.P. Post-pollination hybridization barriers in Nicotiana section Alatae. Sex. Plant Reprod. 2008, 21, 183-195. [CrossRef]

30. Wheeler, M.J.; Franklin-Tong, V.E.; Franklin-Tong, N. The molecular and genetic basis of pollen-pistil interactions. New Phytol. 2001, 151, 565-584. [CrossRef] [PubMed]

31. Zenkteler, M.; Nitzsche, W. Wide hybridization experiments in cereals. Theor. Appl. Genet. 1984, 68, 311-315. [CrossRef]

32. Ram, S.G.; Thiruvengadam, V.; Ramakrishnan, S.H.; Bapu, J.R.K. Investigation on pre-zygotic barriers in the interspecific crosses involving Gossypium barbadense and four diploid wild species. Euphytica 2007, 159, 241-248. [CrossRef]

33. Parton, E. Flower Biology and Crossing Barriers in Bromeliaceae. Ph.D. Thesis, Katholieke Universiteit Leuven, Leuven, Belgium, 2001.

34. Zinkl, G.; Zwiebel, B.; Grier, D.; Preuss, D. Pollen-stigma adhesion in Arabidopsis: A species-specific interaction mediated by lipophilic molecules in the pollen exine. Development 1999, 126, 5431-5440. [CrossRef] [PubMed] 
35. Edlund, A.F.; Swanson, R.; Preuss, D. Pollen and Stigma Structure and Function: The Role of Diversity in Pollination. Plant Cell 2004, 16, S84-S97. [CrossRef] [PubMed]

36. Dinesh, M.; Rekha, A.; Ravishankar, K.; Praveen, K.; Santosh, L. Breaking the intergeneric crossing barrier in papaya using sucrose treatment. Sci. Hortic. 2007, 114, 33-36. [CrossRef]

37. Wolters-Arts, M.; van der Weerd, L.; Van Aelst, A.C.; Van As, H.; Mariani, C. Water-conducting properties of lipids during pollen hydration. Plant Cell Environ. 2002, 25, 513-519. [CrossRef]

38. Boavida, L.C.; McCormick, S. Temperature as a determinant factor for increased and reproducible in vitro pollen germination in Arabidopsis thaliana. Plant J. 2007, 52, 570-582. [CrossRef]

39. Ma, J.-F.; Liu, Z.-H.; Chu, C.-P.; Hu, Z.-Y.; Wang, X.-L.; Zhang, X.S. Different regulatory processes control pollen hydration and germination in Arabidopsis. Sex. Plant Reprod. 2011, 25, 77-82. [CrossRef] [PubMed]

40. Fratini, R.; Ruiz, M.L. Interspecific Hybridization in the Genus Lens Applying In Vitro Embryo Rescue. Euphytica 2006, 150, 271-280. [CrossRef]

41. Matzk, F. Hybrids of Crosses between Oat and Andropogoneae or Paniceae Species. Crop. Sci. 1996, 36, 17-21. [CrossRef]

42. Sidhu, P.K.; Howes, N.K.; Aung, T.; Zwer, P.K.; Davies, P.A. Factors affecting oat haploid production following oat $\times$ maize hybridization. Plant Breed. 2006, 125, 243-247. [CrossRef]

43. Wędzony, M.; Van Lammeren, A.A.M. Pollen tube growth and early embryogenesis in wheat $\times$ maize crosses influenced by 2 , 4-D. Ann. Bot. 1996, 77, 639-647. [CrossRef]

44. Koltunow, A.M.; Grossniklaus, U. Apomixis: A Developmental Perspective. Annu. Rev. Plant Biol. 2003, 54, 547-574. [CrossRef] [PubMed]

45. Mulcahy, G.B.; Mulcahy, D.L. A comparison of pollen tube growth in bi-and trinucleate pollen. Pollen Biol. Implic. Plant Breed. 1983, 29-33. 